\title{
Genetic relationships between muscle density, measured by X-ray computed tomography (CT), and lamb growth and carcass traits
}

N R Lambe, J Conington, E A Navajas, K A McLean, R Roehe, L Bunger

SAC, Edinburgh, United Kingdom

Email: Nicola.Lambe@sac.ac.uk

Introduction With successful selection for leanness and muscularity in different sheep breeds, care must be taken to ensure that carcass composition is not changed in a way that is detrimental to meat quality. Recent research in different sheep breeds has found that average muscle density (MD) measured in-vivo in cross-sectional CT scans has strong negative genetic and phenotypic correlations with intramuscular fat (IMF), as well as taste panel scores for flavour, juiciness and palatability (Karamichou et al., 2006, Navajas, 2008). Therefore, CT provides the means to quantify IMF (and potentially other meat quality traits), at the same time as carcass fat and muscle, in live lambs, which could be exploited in selection programmes. Genetic parameters are required for MD, including estimates of correlations with other growth and carcass traits, before its inclusion in breeding programmes can be assessed.

Materials and methods Performance and pedigree data were available from Scottish Blackface lambs from two hill farms of contrasting severity, giving a total of approximately 16800 lamb records collected over 15 years. At weaning, live weight (WWT) was recorded, as well as ultrasonically-measured (US) fat depth (UFD) and muscle depth (UMD). A sample of lambs from each farm was CT scanned at weaning in four years, giving a total of 844 lambs scanned. Total weights of carcass fat (CFAT), muscle (MUSC), internal fat (IFAT) and bone (BONE) were predicted from CT scans (Lambe et al., 2006). In the hind leg and loin regions of the body, muscle volume (HLMV and LRMV, respectively) and muscularity indices (HLMI and LRMI, respectively) were calculated (Navajas et al., 2007). MD was calculated in three cross-sectional reference scans, taken at the leg, loin, and chest, and averaged (MD in each scan weighted by proportion of muscle area in that scan across the data set - i.e. ISCMD x 0.5, LV5MD x 0.27, TV8MD x $0.23=$ AVMD). Surplus lambs were slaughtered when they reached commercial slaughter criteria (minimum live weight $\sim 37.5 \mathrm{~kg}$ and condition score 3 ). Carcass records ( 7300 in total) included hot carcass weight (CWT) and MLC classification scores for fatness (MLCF; scored on a 7 point scale and transformed to estimated subcutaneous fat percentage) and conformation (MLCC; scored on a 5 point scale). Using ASREML (Gilmour et al., 2001), the heritability of AVMD was estimated using a univariate analysis, whilst genetic $\left(r_{g}\right)$ and phenotypic $\left(r_{p}\right)$ correlations between AVMD and other lamb traits were estimated using bivariate analyses. For each trait, a model was fitted that included random effects of animal and maternal permanent environment and fixed effects of age, farm, year, sex, litter size at 1 week, dam age, grazing area, and interactions of farm with year and sex.

Results AVMD was moderately heritable $\left(\mathrm{h}^{2}=0.30\right.$, s.e. 0.09$)$. Phenotypic correlations (Table 1) with weights and carcass traits measured in-vivo were low to moderate and negative, suggesting that larger lambs with more fat and muscle and greater muscularity had less dense muscle (linked to better meat quality). However, only genetic correlations with UFD and CFAT were significantly different from zero, suggesting a negative genetic association of MD with fatness, but no significant association with muscling or muscularity. Neither $r_{g}$ (range: -0.03 to -0.08 ) nor $r_{p}$ (range: 0.01 to 0.04 ) with carcass traits (CWT, MLCC, MLCF) differed significantly from zero.

Conclusions The results suggest that inclusion of MD as a predictor of IMF, or other meat quality traits, in sheep breeding programmes would not be antagonistic with breeding goals aimed at increasing muscling, muscularity or growth. Unfavourable genetic associations with fat measurements support the case for including predictors of both carcass fat and IMF in breeding programmes, to optimise carcass and meat quality simultaneously. Similar results were reported by Navajas (2008) in the Texel breed, although further larger studies in terminal sire breeds would be relevant.

Acknowledgements Financial support for this research was received from the Scottish Government and Defra. The authors are grateful to staff at SAC Kirkton and Castlelaw farms and the CT unit for data collection.

\section{References}

Gilmour AR, Cullis BR, Welham SJ and Thompson R 2001. ASREML Reference Manual. NSW Agriculture, Orange, Australia

Karamichou E, Richardson RI, Nute GR, McLean KA and Bishop SC 2006. Animal Science 82, 151-162

Lambe NR, Conington J, McLean KA, Navajas EA, Fisher AV and Bünger L 2006. Journal of Animal Breeding and Genetics 123, 105-113

Navajas EA 2008. PhD thesis. University of Edinburgh

Navajas EA, Lambe NR, McLean KA, Glasbey CA, Fisher AV, Charteris AJL, Bunger L and Simm G 2007. Meat Science $75,533-542$. 